\title{
Application of Alumina to Oil and Grease Removal from Refinery Effluent
}

\section{Abhinav Norisetty,Jayanta Kumar Basu and Sonali Sengupta*}

Department of Chemical Engineering, Indian Institute of Technology, Kharagpur,India -721302

\begin{abstract}
Alumina was synthesised by surface hydrolysis of thin aluminium plate and then applied as an adsorbent to treat the refinery effluent water to reduce the levels of COD(Chemical Oxygen Demand), BOD(Biological Oxygen Demand) and $O G(O i l$ and Grease) content in the effluent to satisfy the prescribed limit. The prepared alumina was characterized based on BET surface area, X-ray diffraction analysis and scanning electron microscopy. The effects of the amount of adsorbent, temperature and the dilution of the effluent on the reduction of COD, BOD and OG levels were studied. COD, BOD and OG reduction were observed to be $87.83 \%, 86.6 \%$ and $83 \%$ at $20^{\circ} \mathrm{C}$ with an alumina dose of $15 \mathrm{gms}$ per $100 \mathrm{ml}$ effluent. In the equilibrium study, it has been noted that the adsorption capacities of alumina for COD and OG at equilibrium are linearly co-related. The adsorption is of first order and the initial rate constant obtained is $3 \times 10^{-6} \mathrm{~min}^{-1}$ at $20^{\circ} \mathrm{C}$.
\end{abstract}

Keywords: Alumina; Characterization; Sorption; Equilibrium; Rate constant

\section{Introduction}

Waste waters released by crude oil-processing industries are characterized by the presence of large quantities of crude oil products, polycyclic and aromatic hydrocarbons, phenols, metal and surfaceactive substances which comprises grease and other chemicals [1]. The presence of these objectionable materials in water has to be monitored before it is released from refinery to the environment because it raises COD (Chemical Oxygen Demand) and BOD (Biological Oxygen Demand) level in the water body. The high levels of COD and BOD and OG in water inhibits the growth of micro-organisms in the water disturbing the ecological balances which consequently affects the human health. Oil and grease can also affect the fertility of the land. As per Bureau of Indian Standard specification [2] COD, BOD and oil and grease levels in inland surface water should be kept below 250, 30 and $10 \mathrm{mg} / \mathrm{L}$ respectively.

Adsorption is one of the most common and efficient method for removal of objectionable material from polluted water.

Alumina $\left(\mathrm{Al}_{2} \mathrm{O}_{3}\right)$ is a porous material that is extensively used as an adsorbent. Due to its high adsorption capacity and surface area, it is widely used to remove metal ions $[3,4]$, dyes $[5,6]$ and organic acid and solvents $[7,8]$ from solutions. Application of alumina as an adsorbent for water treatment is well known. Tests on the adsorption of As (V) and $\mathrm{Cu}$ on mesoporous alumina were carried out under batch process with high rates of adsorption were found in a broad range of $\mathrm{pH}$ with various loading [9-11]. Yu et al. [12] prepared mesoporous alumina using cationic surfactant, which showed a very high surface area and highly improved adsorption capacity.

Activated alumina was used to reduce the TDS content from 2000 to $850 \mathrm{mg} / \mathrm{L}$ and fluoride content from 14 to around $7 \mathrm{mg} / \mathrm{L}$ [13]. Activated alumina with potassium permanganate and activated carbon were employed as adsorbent for removal of volatile organic carbon [14].

So, it can be inferred that alumina has application as an adsorbent for removal of different water pollutants. Based on the results of these prior studies it seems plausible that alumina would be a good adsorbent for oil and grease from industrial effluent.

The objective of the present work is to prepare alumina and its characterization based on BET (Brunauer-Emmett-Teller isotherm), XRD (X-ray diffraction) and SEM (Scanning electron microscopy) measurements and the application of the alumina for removal of oil and grease from refinery effluent. The kinetics of the adsorption was also investigated.

\section{Materials and Methods}

Alumina was prepared, characterized and applied for removal of oil and grease from refinery effluent. Aluminium plates of thickness $1.5 \mathrm{~mm}$ were cut into $8 \mathrm{~cm} \times 4 \mathrm{~cm}$; the surfaces were cleaned and washed with distilled water. Pure aluminium is an active metal and when exposed to air or water, it instantaneously reacts to form a dense spontaneous surface oxide film of about 3-5 $\mathrm{nm}$ thickness which prevents further surface oxidation. To remove this surface oxide layer the plates were treated with $0.1 \mathrm{M} \mathrm{HCl}$ solution. The surface aluminium oxide reacts to form.

$$
\mathrm{Al}_{2} \mathrm{O}_{3}+6 \mathrm{HCl} \rightarrow 2 \mathrm{AlCl}_{3}+3 \mathrm{H}_{2} \mathrm{O}
$$

The excess acid and the surface oxide layer in the form of aluminium chloride, were removed by repeated washing with distilled water. The water again instantaneously reacts with the refreshed Al-metal surface and adds a new surface oxide in a thin layer.

Then the plates were treated with a $0.1 \mathrm{M}$ solution of mercuric chloride for a short period to remove the stable surface oxide layer and to induce hydrolysis. It results a clean oxide-free nascent Al-surface. In order to perform the hydrolysis of aluminium, the clean plates were immersed in distilled water in a glass beaker. Finally a porous $\mathrm{Al}_{2} \mathrm{O}_{3}$ powder was prepared by dehydration of the intermediate product $\mathrm{AlO}(\mathrm{OH}) \cdot \alpha \mathrm{H}_{2} \mathrm{O}$ at $275^{\circ} \mathrm{C}$.

*Corresponding author: Sonali Sengupta, Department of Chemical Engineering Indian Institute of Technology, Kharagpur,India -721302, Tel: +91-3222-283954, Fax : +91-3222-282250; E-mail: sonalis@che.iitkgp.ernet.in

Received May 31, 2011; Accepted August 29, 2011; Published August 31, 2011

Citation: Norisetty A, Basu JK, Sengupta S (2011) Application of Alumina to Oil and Grease Removal from Refinery Effluent. Hydrol Current Res 2:119. doi:10.4172/2157-7587.1000119

Copyright: (c) 2011 Norisetty A, et al. This is an open-access article distributed under the terms of the Creative Commons Attribution License, which permits unrestricted use, distribution, and reproduction in any medium, provided the original author and source are credited. 
$\mathrm{Al}+(+2) \mathrm{H}_{2} \mathrm{O} \rightarrow \mathrm{AlO}(\mathrm{OH}) \alpha \mathrm{H}_{2} \mathrm{O}+1.5 \mathrm{H}_{2}$

The transformation to $\mathrm{Al}_{2} \mathrm{O}_{3}$ phase was performed by calcining at 300 to $1050^{\circ} \mathrm{C}$ for 5 hours to get two different $\mathrm{Al}_{2} \mathrm{O}_{3}$ samples.

The X-ray diffraction studies on the samples were carried out with PAN Analytical PW-3050/60 diffractometer, using copper-Ka radiation. BET surface area, pore size and pore volume analysis were obtained by Quantachrome AUTOSORB AS1 surface area and poresize analyzer. HRTEM analysis was done using JEOL 2100 instrument operated at accelerating voltage $200 \mathrm{kV}$. SEM was performed using the instrument Hitachi model SU-70.

The refinery effluent was obtained from effluent treatment plant of Haldia Refinery, Indian Oil Corporation Limited, Haldia, India which has average oil and grease content of $192 \mathrm{mg} / \mathrm{L}$.

A typical alumina sample was selected based on the characteristic properties and the adsorption capacity for oil and grease of this alumina was investigated in batch adsorption process. A number of $500 \mathrm{ml}$ stoppered conical flasks containing $250 \mathrm{ml}$ effluent with 5 to 15 grams of alumina powder were agitated in a mechanical shaker till equilibrium. The experiment was performed at two different temperatures $20^{\circ} \mathrm{C}$ and $50^{\circ} \mathrm{C}$. Samples were analysed for oil and grease, COD and BOD using standard methods [15]. Effects of different parameters on the removal of oil and grease were observed at temperatures: $20-50^{\circ} \mathrm{C}$; initial oil and grease content, COD and BOD in the sample: 192, 148 and $120 \mathrm{mg} / \mathrm{L}$ respectively and alumina loading: 2-15 gm.

\section{Result and Discussion}

\section{Characterisation of alumina}

$\mathrm{XRD}$ results aluminum hydroxide calcined at temperatures 300 and $600^{\circ} \mathrm{C}$ for $5 \mathrm{hr}$ are shown in Figure 1. The transformation of boehmite state to $\gamma-\mathrm{Al}_{2} \mathrm{O}_{3}$ occurs heating at $600^{\circ} \mathrm{C}[16,17]$. As the calcination temperature increases the crystalinity of the sample is increased.

The BET surface area, pore size, and pore volume of the samples of alumina are listed in Table 1. It can be seen that with increasing temperature, the surface area of the sample increases from $279 \mathrm{~m}^{2} / \mathrm{gm}$ at $300^{\circ} \mathrm{C}$ to $477 \mathrm{~m}^{2} / \mathrm{gm}$ at $600^{\circ} \mathrm{C}$, and correspondingly the pore volume increases from 0.247 to $0.436 \mathrm{cc} / \mathrm{g}$. When the temperature increases from 600 to $1050^{\circ} \mathrm{C}$, however, a quick decrease in the surface area was observed.

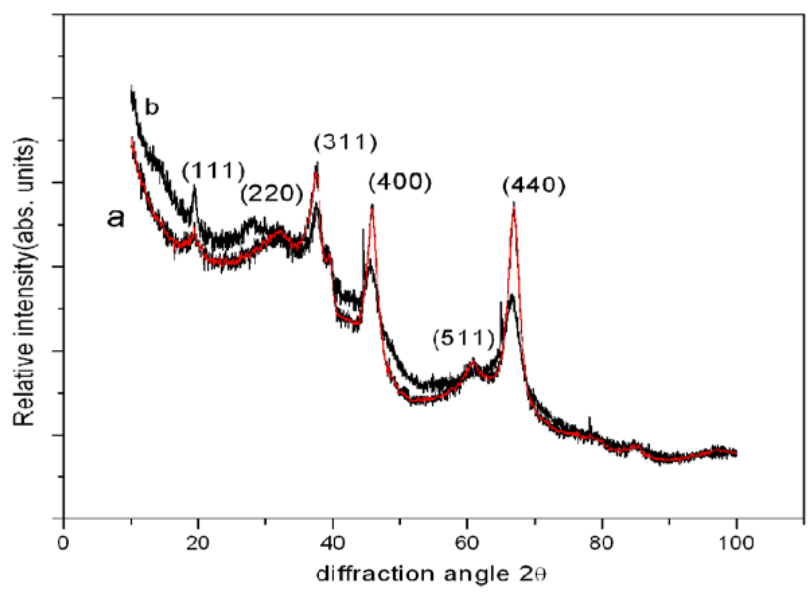

Figure 1: XRD of alumina after calcination at $300^{\circ} \mathrm{C}(\mathrm{a})$ and $600^{\circ} \mathrm{C}(\mathrm{b})$.

\begin{tabular}{|l|l|l|l|}
\hline $\begin{array}{l}\text { Calcination } \\
\text { Temperature }\left({ }^{\circ} \mathrm{C}\right)\end{array}$ & $\begin{array}{l}\text { Pore size } \\
(\mathrm{nm})\end{array}$ & $\begin{array}{l}\text { BET surface area } \\
\left(\mathrm{m}^{2} / \mathrm{g}\right)\end{array}$ & $\begin{array}{l}\text { Pore volume } \\
\mathrm{cm}^{3} / \mathrm{g}\end{array}$ \\
\hline 300 & 1.173 & 279 & 0.247 \\
\hline 600 & 1.27 & 477 & 0.4365 \\
\hline 800 & 3.69 & 385 & 0.953 \\
\hline 1050 & 3.672 & 228 & 0.852 \\
\hline
\end{tabular}

Table 1: Surface area, pore size and pore volume of synthesized alumina samples.

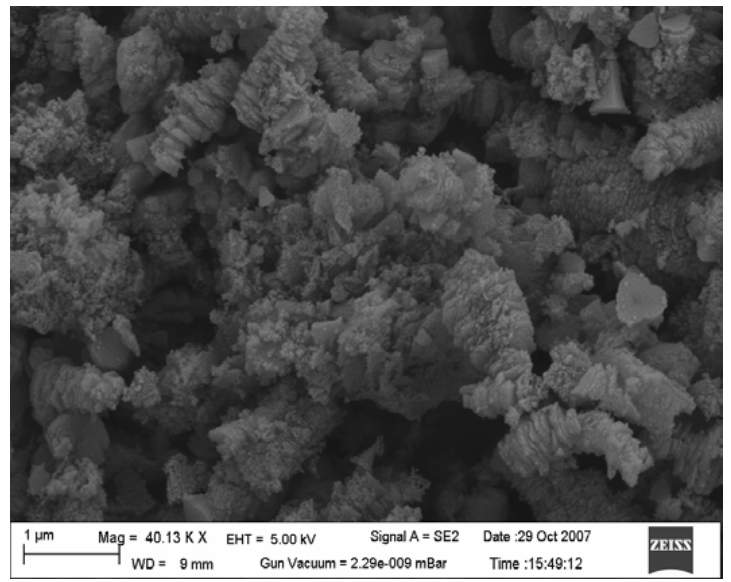

Figure 2: SEM micrographs of alumina calcined at $600^{\circ} \mathrm{C}$.

\begin{tabular}{|l|l|l|}
\hline Elements & weight percent & Atomic (\%) \\
\hline $\mathrm{Al}$ & 52.44 & 39.39 \\
\hline $\mathrm{Hg}$ & 0.85 & 00.09 \\
\hline $\mathrm{O}$ & 46.71 & 59.98 \\
\hline Total & 100.00 & 100.00 \\
\hline
\end{tabular}

Table 2: Quantitative chemical analysis of alumina calcined at $600^{\circ} \mathrm{C}$.

From the above observation, it is clear that the alumina calcined at $600^{\circ} \mathrm{C}$ has the highest surface area and is in stable $\gamma-\mathrm{Al}_{2} \mathrm{O}_{3}$ form. So, this alumina was chosen for treating refinery effluent.

The micro structure of this representative $\mathrm{Al}_{2} \mathrm{O}_{3}$ sample has been analyzed with SEM micrographs to obtain morphology which is shown in Figure 2. The micrograph hardly represents a resolved structure of particles or crystallites with a definite size or morphology. Quantitative compositional analysis of prepared alumina calcined at $600^{\circ} \mathrm{C}$ was determined by EDS spectrum obtained from SEM and is represented in Table 2.

\section{Application in removal of oil and grease}

The alumina calcined at $600^{\circ} \mathrm{C}$ is applied as an adsorbent for removal of oil and grease from refinery effluent to find out the adsorption capacity of alumina and results are as follows:

A 0.5 serial dilution of the effluent was used to establish a concentration gradient in terms of \% raw effluent ranging from 25$100 \%$. The variation of COD, oil and grease and BOD were determined with sample dilution and presented in the form of histogram in Figure 3. COD values are the greatest among the three.

The degree of agitation has been varied by changing stirrer speed from 600 to $2200 \mathrm{rpm}$ to determine the drop in COD values with time in the adsorption experiments conducted in presence of alumina. This result has been depicted in Figure 4. It was observed that as the stirrer speed increases, the drop in COD value increases. The plots obtained 
for 1800 and $2200 \mathrm{rpm}$ are very close, which clearly proves that the external mass transfer effect is negligible beyond $2200 \mathrm{rpm}$.So all the consequent adsorption experiments was carried out at $1800 \mathrm{rpm}$.

The effluent from the refinery was treated with varying amount of alumina at $20^{\circ} \mathrm{C}$ and the fraction removed was plotted against time. The fractional drop of oil and grease, COD and BOD levels in the effluent has been calculated by using the following general equation

$$
f_{i}=\frac{C_{0, i}-C_{i}}{C_{0, i}},
$$

where i stands for different constituents in the effluent.

So, we can express the adsorption capacity $q_{i}=\frac{\left(C_{0, i}-C_{i}\right)}{m} V$

From Equations (1) and (2), $q=f \cdot C_{0} \cdot \frac{\mathrm{V}}{\mathrm{m}}$

So, the rate of adsorption can be written as,

$$
r_{a d}=\frac{d q}{d t}=\left(\frac{V}{m} C_{0}\right) \cdot \frac{d f}{d t}
$$

The initial adsorption rate $r_{a d 0}$ was obtained by evaluation of the slope $\frac{d f}{d t}$ at $\mathrm{t}=0$ from the Figure 9 .

Figure 5 has shown that the fractional removal of oil and grease $\left(\mathrm{f}_{\mathrm{OG}}\right)$, at the preliminary stage, is significant and then gets leveled off as per usual trend. For the sake of comparison, choosing a typical point of time, $30 \mathrm{~min}$, the fractional removal of oil and grease in the effluent are found to be $0.57,0.61$ and $0.68 \mathrm{mg} / \mathrm{L}$ for 5,10 and $15 \mathrm{~g}$ of alumina respectively.

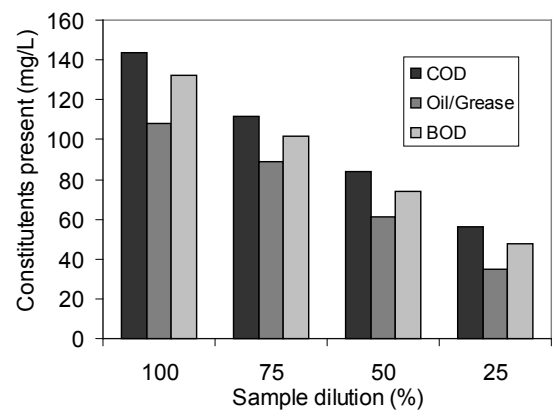

Figure 3: Variation of COD, Oil and Grease and BOD with dilution.

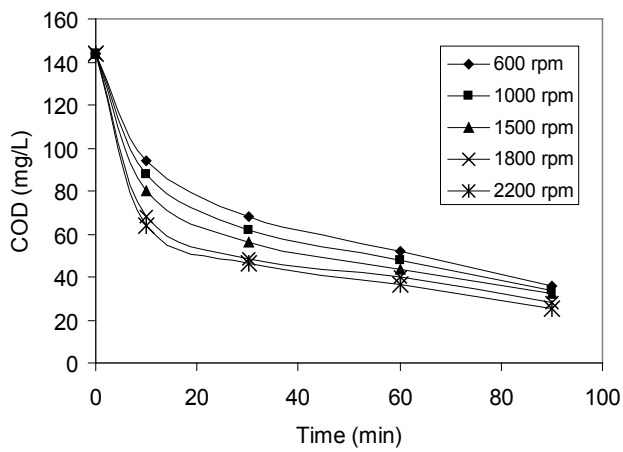

Figure 4: Effect of speed of agitation on COD.

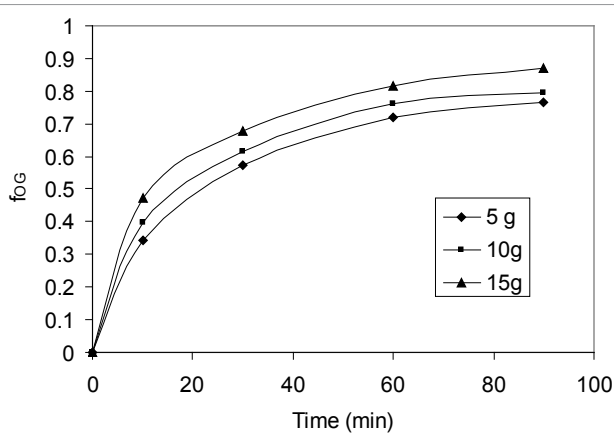

Figure 5: Effect of amount of alumina on oil and grease removal at $20^{\circ} \mathrm{C}$

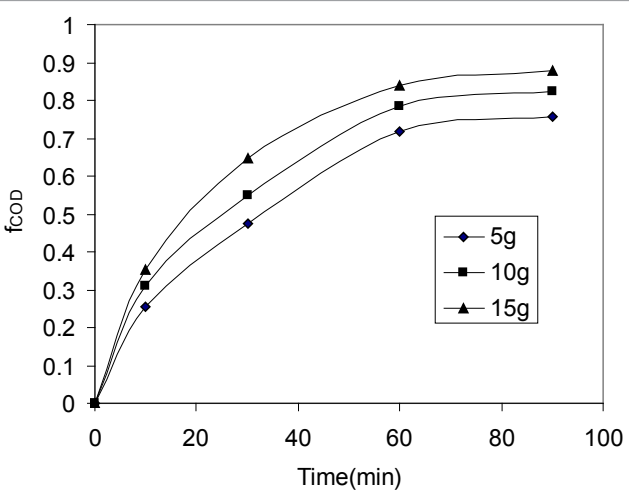

Figure 6: Effect of amount of alumina on $\mathrm{BOD}$ at $20^{\circ} \mathrm{C}$

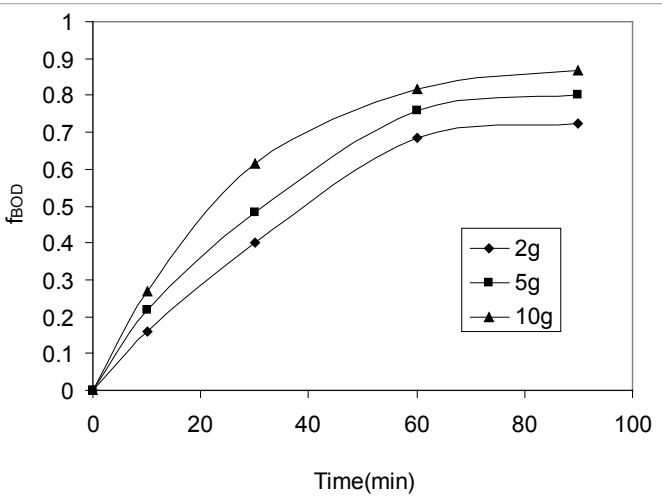

Figure 7: Effect of amount of alumina on $\mathrm{COD}$ at $20^{\circ} \mathrm{C}$

The effect of amount of alumina on fractional COD drop $\left(\mathrm{f}_{\mathrm{COD}}\right)$ is shown in Figure 6. The COD removal profile also follows the similar pattern as that of the oil and grease. The fractional removal of COD reaches at $0.47,0.55$ and $0.65 \mathrm{mg} / \mathrm{L}$ in 30 minutes for 5,10 and $15 \mathrm{~g}$ alumina respectively. Initially COD falls rapidly, almost the same for all the three amounts of adsorbents, and approach to equilibrium starts approximately from $60 \mathrm{~min}$ time.

The fractional fall in BOD values $\left(\mathrm{f}_{\mathrm{BOD}}\right)$ were obtained at different time intervals by treating the raw effluent with 2,5 and $10 \mathrm{~g}$ alumina and the data obtained are shown in Figure 7. The curves with similar trend as COD and oil and grease are noted. In this case, the fractional removal of BOD values is $0.4,0.48$ and $0.62 \mathrm{mg} / \mathrm{L}$ at $30 \mathrm{~min}$ for 2,5 and $10 \mathrm{~g}$ respectively.

The effect of oil and grease concentration in the effluent on 
the fractional adsorption is shown in Figure 8. The oil and grease concentration in the effluent ranges from 108 to $61 \mathrm{mg} / \mathrm{L}$. The fractional adsorption for all the three concentration values show same trend with similar slope. A marginal increase in fractional adsorption has been observed with increase in concentration. The slope at $\mathrm{t}=0$ is obtained and initial rate of adsorption $r_{a d 0}$ is calculated from the Equation (4). The results are shown in Table 3(a) and (b) for alumina content and oil and grease content respectively. $r_{a d 0}$ was plotted against concentration of oil and grease, $\mathrm{C}_{0}$, in Figure 9. The slope of the straight line obtained gives the adsorption rate constant $\mathrm{k}_{\mathrm{ad}}$ as $3 \times 10^{-6} \mathrm{~min}^{-1}$ and the adsorption is of first order in nature.

The percentage removal of oil and grease, drop in COD and BOD values with two different temperatures, $20^{\circ}$ and $50^{\circ} \mathrm{C}$ are shown in the Figure 10. The removal of all three constitutents is temperature dependent as the removal percentage increased with a rise in

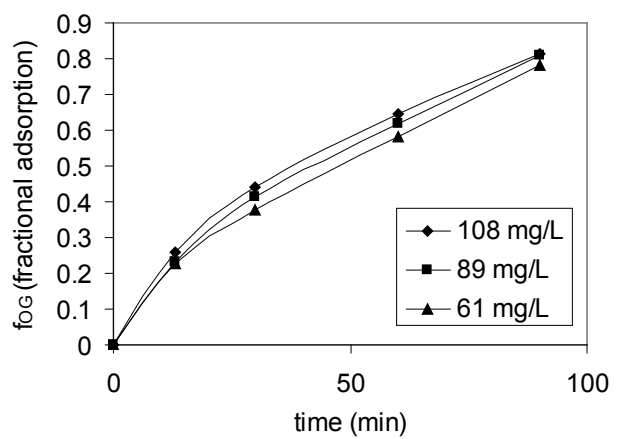

Figure 8: Effect of oil and grease concentration on $\mathrm{f}_{\mathrm{OG}}$.

\begin{tabular}{|l|l|l|}
\hline Alumina content $(\mathrm{g})$ & $\mathrm{df} / \mathrm{dt}$ & $\mathrm{r}_{\text {ado }}$ \\
\hline 5 & 0.0343 & 0.000329 \\
\hline 10 & 0.035 & 0.000168 \\
\hline 15 & 0.037 & 0.000118 \\
\hline
\end{tabular}

Table 3(a): Effect of alumina content on initial adsorption rate $\left(r_{\text {ado }}, \mathrm{mg} / \mathrm{g}\right.$ adsorbent.sec) (concentration of oil and grease: $192 \mathrm{mg} / \mathrm{L}$ ).

\begin{tabular}{|l|l|l|}
\hline $\mathrm{C}_{\mathrm{OG}}(\mathrm{mg} / \mathrm{L})^{*}$ & $\mathrm{df} / \mathrm{dt}$ & $\mathrm{r}_{\text {ad } 0}$ \\
\hline 108 & 0.026 & 0.000351 \\
\hline 89 & 0.0233 & 0.000259 \\
\hline 61 & 0.0229 & 0.000174 \\
\hline
\end{tabular}

${ }^{*} \mathrm{C}_{\mathrm{OG}}$ is oil and grease content in $\mathrm{mg} / \mathrm{L}$

Table 3(b): Effect of concentration of oil and grease on initial adsorption rate $\left(r_{\text {ado }}\right.$ mg/g-adsorbent.sec) (amount of alumina : $2 \mathrm{~g}$ ).

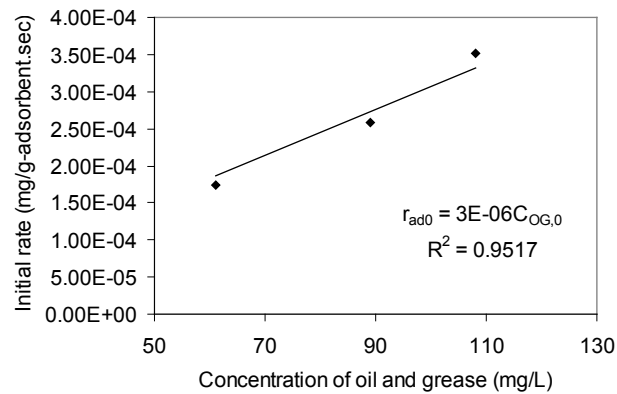

Figure 9: Effect of concentration of oil and grease on initial rate of adsorption.

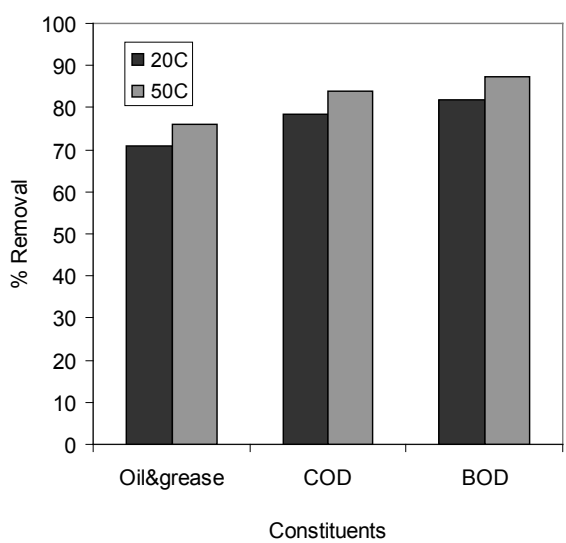

Figure 10: Effect of temperature on percentage removal of oil and grease, $C O D$ and BOD.

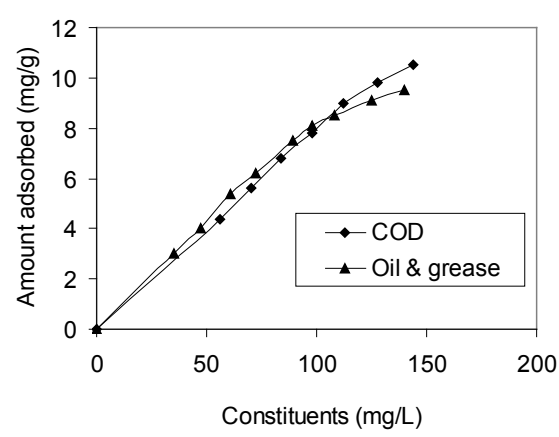

Figure 11: Equilibrium curve for oil and grease and COD.

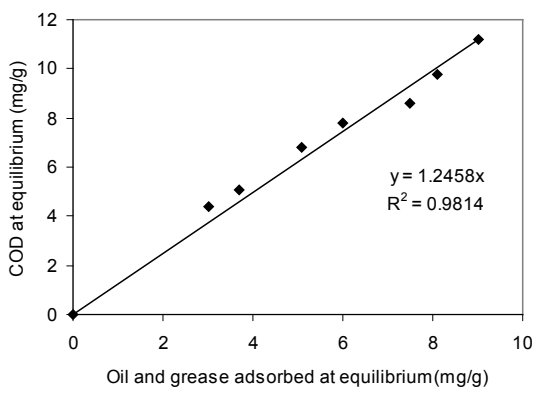

Figure 12: Relation between COD and oil and grease adsorbed at equilibrium

temperature. From this observed it can be inferred that the adsorption is due to chemisorption.

The adsorption equilibrium with respect to oil and grease and COD with adsorbent alumina was studied and the contents of oil and grease and $\mathrm{COD}$ at equilibrium in effluent solution was plotted against the two species adsorbed on the solid surface of the adsorbent in $\mathrm{mg} / \mathrm{g}$. This plot has been shown in Figure 11. It was observed that the equilibrium curves for COD and oil and grease are very close to each other.

A known quantity of adsorbent alumina is added in the effluent of different concentrations of COD and oil and grease in different conical flasks. The adsorption loading onto the surface in terms of 
COD are different when the system reached at equilibrium. Oil and grease adsorbed is plotted against COD at equilibrium for different dilution in Figure 12 and it was observed that COD and oil and grease concentrations on solid surface are well correlated in a straight line relationship with correlation coefficient 0.98 . The relation is given by $\mathrm{COD}=1.2458$ (Oil and grease)

\section{Conclusion}

$\gamma-\mathrm{Al}_{2} \mathrm{O}_{3}$ powder was prepared from pure aluminum plate and the alumina powder was characterized. The prepared powder was utilized in the treatment of refinery effluent water. Oil and grease present in the sample was adsorbed in alumina and the fractional removal of oil and grease and drop in COD and BOD values of the effluent were determined. It was found that the prepared alumina presented an excellent performance towards adsorption of oil and grease through decrease in both the COD and BOD level below the allowable limit. The rate of adsorption was found to fit first order rate kinetics with rate constant value $3 \times 10^{-6} \mathrm{~min}^{-1}$ at $20^{\circ} \mathrm{C}$.

\section{References}

1. Suleimanov RA (1995) Conditions of waste fluid accumulation at petrochemical and processing enterprises and prevention of their harm to water bodies. Med Tr Prom Ekol 12: 31-36.

2. IS: 2490 (Part I) (1974) Tolerance limits of Industrial Effluents Discharged into Inland Surface Water, ISI, New Delhi India.

3. Khan SA, Riaz-Ur-Reman, Khan MA (1995) Adsorption of Cs(I), Sr(II) and $\mathrm{Co}(\mathrm{II})$ on $\mathrm{Al}_{2} \mathrm{O}_{3}$. J Radioanalytical and Nuclear Chem 190: 81-96.

4. Saleem M, Afzal M, Mahmood F, Ali A (1992) Surface characterization and thermodynamics of adsorption of $\mathrm{Pr}, \mathrm{Nd}$ and $\mathrm{Er}$ on alumina for aqueous solution. Adsorp Sci Technol 9: 17-29.

5. Iqbal MJ, Ashiq MN (2010) Thermodynamics and kinetics of adsorption of dyes from aqueous media and onto alumina. J Chem Soc Pak 32: 419-428.
6. Saleem M, Afzal A, Naeem TM, Mahmood F, (1994) Adsorption characteristics of organic dyes on alumina powder from aqueous solutions. Adsorp Sc Technol 11: 95-104.

7. Afzal A, Hamdani K, Ahmad H (1990) Thermodynamics of adsorption of organic acids from aqueous solutions on neutral alumina. Sci Intl (LHR) 2: 101-106.

8. Afzal M, Khan M, Ahmad H, (1991) Surface Characterization and heat of adsorption of chromatographic alumina gel. Colloid Polym Sci 269: 483-489

9. Kim Y, Kim C, Choi I, Rangaraj S, Yi J (2004) Arsenic removal using mesoporous alumina prepared via a templating method. Environ Sci Technol 38: $924-931$

10. Rengaraj S, Kim Y, Joo CK, Yi J (2004) Removal of copper from aqueous solution by aminated and protonated mesoporous aluminas: kinetics and equilibrium. J Colloid Interface Sci 273: 14-21.

11. Guana XH, Sub T, Wang J (2009) Quantifying effects of $\mathrm{pH}$ and surface loading on arsenic adsorption on nanoactive alumina using a speciation-based model. J Hazard Mater 166: 39-45.

12. Yu MJ, Li X, Ahn WS (2008) Adsorptive removal of arsenate and orthophosphate anions by mesoporous alumina.Microporous and Mesoporous Mat 113: $197-$ 203.

13. Lee DR, Hargreaves JM, Badertscher L, Rein L, Kassir F (1995) Reverse osmosis and activated alumina water treatment plant for the California State prisons located near Blythe. Desalination 103: 155-161.

14. Guo BB, Jianshun SZ, Nair S, Chen W, Smith J (2006) VOC removal rrformance of pellet/granular-type sorbent media--experimental results. ASHRAE transactions 112: 430-440.

15. Methods of sampling and test (physical and chemical) for water and waste water: Part 39 Oil and grease, IS 3025 (Part 39): (1989) Bureau of Indian Standard, New Delhi.

16. Parida KM, Pradhan AC, Das J, Sahu N (2009) Synthesis and characterization of nano-sized porous gamma-alumina by control precipitation method. Mat Chem and Phy 113: 244-248.

17. Shiau FS, Fang TT (1999) Low-temperature synthesis of a-alumina using citrate process with $\alpha$-alumina seeding. Mat Chem and Phy 60: 91-94. 